\title{
Defective Bone Repair in C57Bl6 Mice With Acute Systemic Inflammation
}

\author{
D. A. Behrends MD, D. Hui BSc, C. Gao MD, PhD, A. Awlia MD, \\ Y. Al-Saran MD, A. Li MD, J. E. Henderson PhD, P. A. Martineau MD
}

Received: 27 June 2016/ Accepted: 3 November 2016/Published online: 14 November 2016

(C) The Association of Bone and Joint Surgeons ( 2016

\begin{abstract}
Background Bone repair is initiated with a local inflammatory response to injury. The presence of systemic inflammation impairs bone healing and often leads to malunion, although the underlying mechanisms remain poorly defined. Our research objective was to use a mouse model of cortical bone repair to determine the effect of
\end{abstract}

The institution of one or more of the authors (JEH, PAM) has received, during the study period, funding from the Fonds de recherche Santé Québec.

The remaining authors certify that neither he or she, nor a member of his or her immediate family, has funding or commercial associations (consultancies, stock ownership, equity interest, patent/licensing arrangements, etc) that might pose a conflict of interest in connection with the submitted article.

All ICMJE Conflict of Interest Forms for authors and Clinical Orthopaedics and Related Research ${ }^{\circledR}$ editors and board members are on file with the publication and can be viewed on request.

Each author certifies that his or her institution approved the animal protocol for this investigation and that all investigations were conducted in conformity with ethical principles of research.

This study was done at the Bone Engineering Laboratories, Research Institute-McGill University Health Centre, Montreal General Hospital Montreal, Quebec, Canada.

D. A. Behrends, D. Hui, C. Gao, A. Awlia, Y. Al-Saran, A. Li, J. E. Henderson, P. A. Martineau

Bone Engineering Laboratories, Research Institute-McGill

University Health Center, Montreal, QC, Canada

D. A. Behrends, A. Awlia, Y. Al-Saran, J. E. Henderson, P. A. Martineau

Experimental Surgery, Faculty of Medicine, McGill University,

Montreal, QC, Canada

C. Gao, J. E. Henderson

Experimental Medicine, Faculty of Medicine, McGill

University, Montreal, QC, Canada systemic inflammation on cells in the bone healing microenvironment.

Question/Purposes (1) Does systemic inflammation, induced by lipopolysaccharide (LPS) administration affect the quantity and quality of regenerating bone in primary bone healing? (2) Does systemic inflammation alter vascularization and the number or activity of inflammatory cells, osteoblasts, and osteoclasts in the bone healing microenvironment?

Methods Cortical defects were drilled in the femoral diaphysis of female and male C57BL/6 mice aged 5 to 9 months that were treated with daily systemic injections of LPS or physiologic saline as control for 7 days. Mice were euthanized at 1 week (Control, $\mathrm{n}=7$; LPS, $\mathrm{n}=8$ ), 2 weeks (Control, $\mathrm{n}=7$; LPS, $\mathrm{n}=8$ ), and 6 weeks (Control, $\mathrm{n}=9$; LPS, $\mathrm{n}=8$ ) after surgery. The quantity (bone volume per tissue volume $[\mathrm{BV} / \mathrm{TV}]$ ) and microarchitecture (trabecular separation and thickness, porosity) of bone in the defect were quantified with time using microCT. The presence or activity of vascular endothelial cells (CD34), macrophages (F4/80), osteoblasts (alkaline phosphatase [ALP]), and osteoclasts (tartrate-resistant acid phosphatase [TRAP]) were evaluated using histochemical analyses.

D. Hui

Microbiology \& Immunology Program, University of British Columbia, Vancouver, BC, Canada

J. E. Henderson $(\square)$

Bone Engineering Labs, Research Institute-McGill University Health Centre, Surgical Research, C10.148.6, Montreal General Hospital, 1650 Cedar Ave., Montreal, QC H3G 1A4, Canada e-mail: janet.henderson@mcgill.ca 
Results Only one of eight defects was bridged completely 6 weeks after surgery in LPS-injected mouse bones compared with seven of nine defects in the control mouse bones (odds ratio [OR], 0.04; 95\% CI, 0.003-0.560; $\mathrm{p}=0.007$ ). The decrease in cortical bone in LPS-treated mice was reflected in reduced BV/TV $(21 \% \pm 4 \%$ vs $39 \% \pm 10 \%$; $\mathrm{p}<0.01)$, increased trabecular separation $(240 \pm 36 \mu \mathrm{m}$ vs $171 \pm 29 \mu \mathrm{m} ; \mathrm{p}<0.01)$, decreased trabecular thickness $(81 \pm 18 \mu \mathrm{m}$ vs $110 \pm 22 \mu \mathrm{m} ; \mathrm{p}=0.02)$, and porosity $(79 \% \pm 4 \%$ vs $60 \% \pm 10 \% ; \mathrm{p}<0.01)$ at 6 weeks postoperative. Defective healing was accompanied by decreased CD34 (1.1 \pm 0.6 vs $3.4 \pm 0.9 ; \mathrm{p}<0.01)$ ALP $(1.9 \pm 0.9$ vs $6.1 \pm 3.2 ; \mathrm{p}=0.03)$, and TRAP $(3.3 \pm 4.7$ vs $7.2 \pm 4.0 ; \mathrm{p}=$ $0.01)$ activity, and increased F4/80 (13 \pm 2.6 vs $6.8 \pm 1.7$; $\mathrm{p}<0.01)$ activity at 2 weeks postoperative.

Conclusion The results indicate that LPS-induced systemic inflammation reduced the amount and impaired the quality of bone regenerated in mouse femurs. The effects were associated with impaired revascularization, decreased bone turnover by osteoblasts and osteoclasts, and by increased catabolic activity by macrophages.

Clinical relevance Results from this preclinical study support clinical observations of impaired primary bone healing in patients with systemic inflammation. Based on our data, local administration of VEGF in the callus to stimulate revascularization, or transplantation of stem cells to enhance bone turnover represent potentially feasible approaches to improve outcomes in clinical practice.

\section{Introduction}

Bone regenerates by primary or secondary fracture healing depending on the mechanical stability of the fracture. Primary fracture healing requires absolute stability. It is associated with minimal callus formation and direct bridging of fracture ends [15]. Secondary fracture healing occurs in the case of relative stability and shows a combination of endochondral and intramembranous bone formation [14]. A healing fracture and the immune system responsible for inflammatory processes share numerous signaling and regulatory mechanisms $[13,45]$. As the initial phase of the bone-healing cascade, inflammation plays a pivotal role in the process of fracture repair during which an early scaffold of the callus is formed [15, 29]. It triggers synthesis of the extracellular matrix, stimulates revascularization, and recruits mesenchymal stem cells (MSCs) and other progenitor cells $[15,25]$. The immune system also exhibits important crosstalk with bone cells during the later phases of secondary bone repair to orchestrate chondrogenesis and endochondral ossification [13, 15]. Furthermore, the macrophages and several inflammatory cytokines are necessary for differentiation of bone marrow MSCs into osteogenic cells that will regenerate and mineralize bone $[10,18]$.

Systemic inflammatory conditions, such as those associated with orthopaedic polytrauma, disrupt the localized and highly regulated inflammatory phase of bone healing and are proposed to underlie clinical complications such as malunion and nonunion [10]. In a rat model it was shown that repair of a stabilized femoral osteotomy in the presence of acute systemic inflammation induced by chest trauma was associated with an increase in granulocytes and a decrease in macrophages during the early soft callus phase of healing [38]. In another study conducted in neutrophil-deficient mice it was concluded that this type of granulocyte was not involved in the disruption of bone repair leading to malunion in the presence of systemic inflammation [27]. Others have investigated bone repair in a mouse model of chronic inflammation and reported reduced vascularization, increased numbers of macrophages, and impaired remodeling of the callus [1]. These studies begin to address the mechanisms underlying impaired bone healing in the presence of systemic inflammation. In the current study we used a mouse model of bone repair to determine: (1) whether systemic inflammation, induced by lipopolysaccharide (LPS) administration affects the quantity and quality of regenerating bone in primary bone healing, and (2) whether systemic inflammation alters vascularization and the number or activity of inflammatory cells, osteoblasts, and osteoclasts in the bone-healing microenvironment?

\section{Materials and Methods}

\section{Overview}

To answer our first question regarding the effect of LPSinduced systemic inflammation on the repair of a cortical bone defect, we generated a mechanically stable, cortical window defect in skeletally mature mouse femurs. MicroCT was used to quantify the amount and quality of bone bridging the defect at 1,2, and 6 weeks postoperative. To answer our second question regarding the effect of systemic inflammation on revascularization and the presence of immune and bone cells in the fracture callus, we quantified staining for vascular endothelial cells, VEGF, macrophages, osteoclasts, and osteoblasts during the same times.

\section{Animals and Surgery}

All animal procedures were performed in strict accordance with a protocol approved by the McGill Facility Animal Care Committee, in keeping with the guidelines of the 
Canada Council on Animal Care. Skeletally mature female and male C57BL6 mice aged 5 to 8 months were purchased from Charles River Laboratories (Montreal, Quebec, Canada). Surgery was performed essentially as described previously $[6,16]$ to generate reproducible, mechanically stable defects. The femur was exposed by blunt dissection and the periosteum carefully removed from the anterolateral aspect of the proximal femur using the third trochanter as the proximal landmark. Bilateral unicortical defects measuring $2 \mathrm{~mm}$ long $\times 1 \mathrm{~mm}$ wide were drilled on the outer aspect of the femur with a 1-mm burr on a Stryker drill (Stryker Canada Inc, Hamilton, Ontario, Canada). One group of mice received intraperitoneal injections of $25 \mu \mathrm{g}$ LPS diluted in $0.1 \mathrm{~mL}$ phosphate buffered saline (PBS) for 7 days starting immediately postoperative. This dose is one-tenth of the lethal dose in mice and was chosen to prevent damage of other organs and allow the mice to survive indefinitely [22]. A second group of mice received an intraperitoneal injection of $0.1 \mathrm{~mL}$ PBS as Controls. Cohorts of Control and LPS-injected mice were euthanized at 1 week (Control, $\mathrm{n}=7$; LPS, $\mathrm{n}=8$ ), 2 weeks (Control, $\mathrm{n}=7 ;$ LPS, $\mathrm{n}=8$ ), and 6 weeks (Control, $\mathrm{n}=9 ;$;PS, $\mathrm{n}=8$ ) postoperative. These times were selected to analyze bone healing during the inflammatory, regenerative, and remodeling phases of mouse bone healing, using established criteria [14]. Femurs were dissected, fixed overnight at $4^{\circ} \mathrm{C}$ in fresh $4 \%$ paraformaldehyde, and stored in PBS at $4^{\circ} \mathrm{C}$ until microCT analyses.

\section{Measurement of Serum Tumor Necrosis Factor (TNF)- $\alpha$}

Serum TNF- $\alpha$ was used as an index of systemic inflammation in mice euthanized at 1 week postoperative [6]. Mice were exsanguinated 2 hours after the final LPS injection, when the highest serum concentration reportedly is found [50], and the serum was assayed using an enzyme-linked immunosorbent assay (ELISA kit; R\&D Systems, Minneapolis, MN, USA). One hundred microliters of serum or standard (31.25 to 2000 $\mathrm{pg} / \mathrm{mL}$ ) was added to a plate coated with mouse TNF- $\alpha$ capture antibody and incubated before adding mouse TNF- $\alpha$ detection antibody. Diluted streptavidin-horseradish peroxidase then was added followed by the addition of tetramethylbenzidine chromogen. After adding $50 \mu \mathrm{L}$ of $2 \mathrm{~N}$ $\mathrm{H}_{2} \mathrm{SO}_{4}$, the absorbance of each well was measured at $450 \mathrm{~nm}$ and $570 \mathrm{~nm}$.

\section{MicroCT Scans and Analyses}

MicroCT scans and quantitative analyses were used to assess bone bridging across the defect and bone architecture according to protocols established in the laboratory
[6, 16]. Scans were captured using a Skyscan 1172 MicroCT scanner (Bruker, Kontich, Belgium) with a $0.5-\mathrm{mm}$ aluminum filter at a voltage of $50 \mathrm{kV}$, current of $200 \mu \mathrm{A}$, and $5 \mu \mathrm{m}$ spatial resolution. Bridging of the bone defect was defined as continuity of bone tissue between the proximal and distal ends of the defect in the mid-sagittal plane, and new bone covering at least 95\% of the defect in the coronal plane. Two different regions of interest (ROI) were selected for analysis of bone volume per tissue volume (BV/TV). ROI A covered a manually delineated cylinder of medullary tissue adjacent to the window defect and ROI B covered the rectangle of new bone occupying the window defect (Fig. 1). The architecture of bone in ROI B was defined using the following parameters: trabecular number, trabecular thickness, trabecular separation, connectivity density (three-dimensional connectivity of bone structures), percentage total porosity, and the number of closed pores.

Histology, Histochemistry, and Immunohistochemistry

Histologic analyses were performed to assess the morphologic features of new bone with time, neovascularization of the repair tissue, and the presence or activity of mast cells, macrophages, osteoclasts, and osteoblast in the repair tissue. Femurs were decalcified in $10 \%$ EDTA and embedded in paraffin for histochemical and immunochemical analyses essentially as described previously [46]. Serial 5- $\mu \mathrm{m}$ thick sections were cut and stained with hematoxylin and eosin to observe morphologic features and with acidified toluidine blue stain $(\mathrm{pH}$ 2.3) to observe mast cells [6] in the repair tissue adjacent to the window defect. Alkaline phosphatase (ALP)-positive osteoblasts were observed by staining with Naphthol ASTR phosphate, N,N-dimethyl formamide, and nitroblue tetrazolium /bromochloroindolyl phosphate in tris-malate buffer ( $\mathrm{pH}$ 9.3). Osteoclasts and other mononuclar tartrateresistant acid phosphatase (TRAP)-positive cells were observed by staining with Naphthol AS-TR phosphate, sodium nitrite, sodium tartrate, and pararosaniline hydrochloride in acetate buffer ( $\mathrm{pH}$ 5.0). Images were captured on a Zeiss Axioskop 40 microscope (Carl Zeiss Canada Ltd, Toronto, Ontario, Canada), and staining concentration quantified using Image $\mathbf{J}$ software $(\mathrm{NIH}$, Bethesda, MD, USA), as described previously [6]. Adjacent sections of decalcified bone were used for immunohistochemical analyses using the following antisera and methyl green as counterstain: CD34 to mark vascular endothelial cells (R\&D Systems), VEGF to mark angiogenesis (Abcam, Cambridge, MA, USA), Cathepsin $\mathrm{K}$ to mark osteoclasts (Abcam), F4/80 to mark M1 

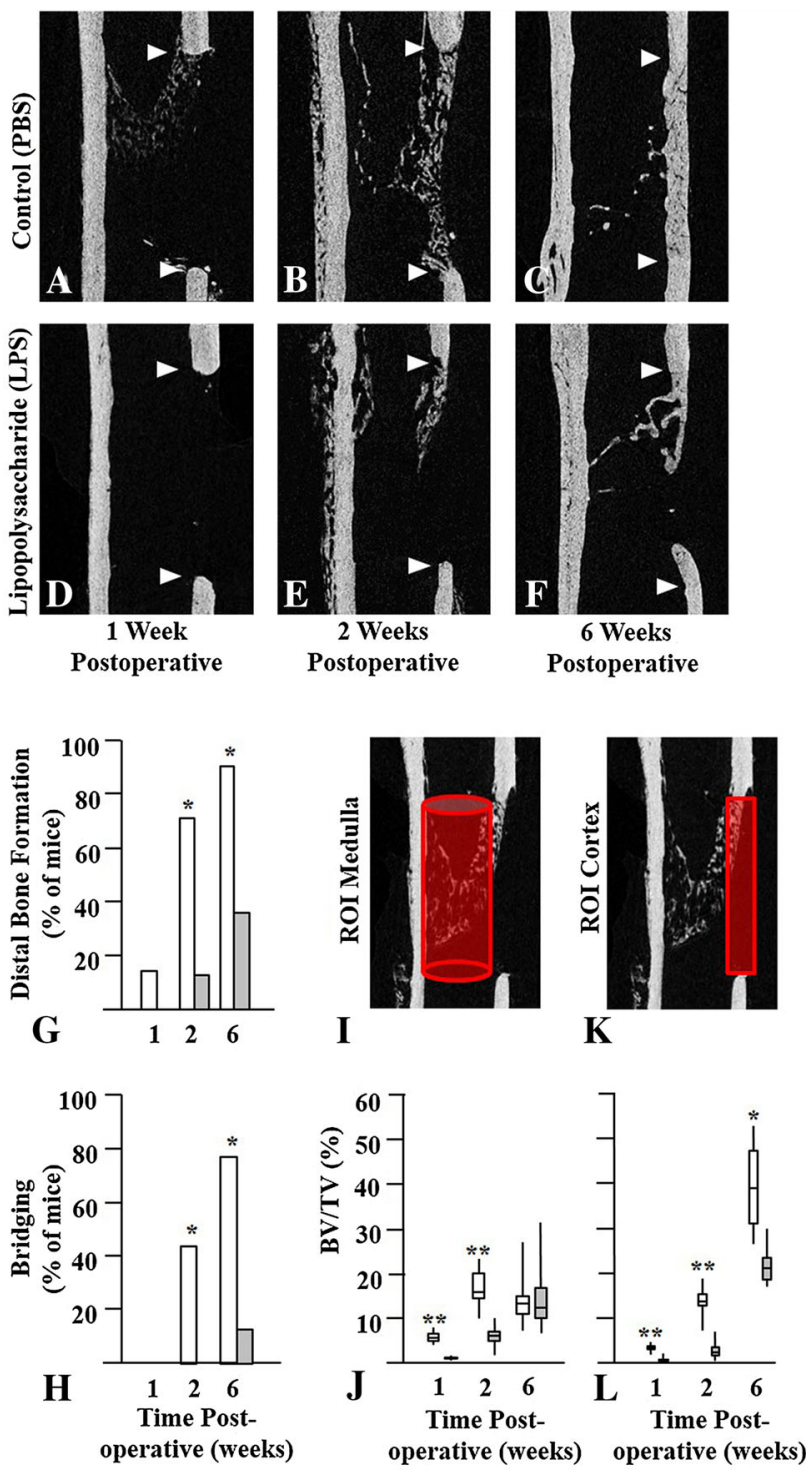

(proinflammatory) and M2 (antiinflammatory, proangiogenic) macrophages (Abcam), and Arginase-1 to mark only M2 macrophages (Santa Cruz Biotechnology Inc, Dallas, TX, USA). Quantification of staining in the ROI (color range: saturation $=0-255$; hue $=0-255$; brightness $=0$ 252) was expressed as a percentage of the total area.

\section{Statistical Analyses}

The average value for left and right femurs was determined for all parameters, and SPSS Version 21 (IBM Corporation, Armonk, NY, USA) was used for the chi-square test (distal bone formation and bridging) and the Mann-Whitney $\mathrm{U}$ test (all other parameters) was used for unpaired samples. Differences were considered significant at a $\mathrm{p}$ less than 0.05 .
4Fig. 1A-L Bilateral femoral window defects were generated in skeletally mature mice, and daily intraperitoneal injections of phosphate buffered saline (PBS) or lipopolysaccharide (LPS) were administered for the first 7 days postoperative. Cohorts of mice were euthanized at 1,2 , or 6 weeks postoperative. Femurs were isolated and scanned at a resolution of $5 \mu \mathrm{m}$ on a Skyscan 1172 microCT instrument. Representative images of the mid-sagittal region with the defects delineated by arrowheads are shown at 1,2, and 6 weeks postoperative. The upper arrowhead indicates the proximal end of the defect while the lower arrowhead indicates the distal end of the defect. In mice injected with PBS (Control) new bone was seen at the proximal end of the defect at (A) 1 week postoperative, (B) at proximal and distal ends at 2 weeks, and (C) bridging the gap at 6 weeks postoperative. In mice injected with LPS there was little new bone at the (D) proximal end at 1 week or at the (E) distal end at 2 weeks, and (F) most defects failed to bridge by 6 weeks postoperative. (G) Distal bone formation and $(\mathbf{H})$ cortical bridging were decreased in LPS-treated mice (grey bars) compared with Control mice (white bars) at all times. Quantitative analyses of new bone were performed in the (I) medullary canal and in the (K) cortical gap and the results are presented as bar graphs. Bone volume per tissue volume (BV/TV) in the (J) medulla and (L) cortex of LPS-treated mice also was reduced at 1 and 2 weeks postoperative. By 6 weeks postoperative medullary bone was similar but cortical bone remained reduced in the LPS-treated mice compared with Control mice. Results are expressed as median with 25 th to 75 th quartiles and ranges. Significantly different from LPS-injected mice; $* \mathrm{p}<0.01 ; * * \mathrm{p}<$ $0.001 ; \mathrm{ROI}=$ region of interest.

\section{Results}

Relationship of LPS-induced Systemic Inflammation to Bone Healing

The dose of LPS used to induce systemic inflammation during the first week of bone repair resulted in elevated circulating TNF- $\alpha$, a reduction of bone in repair tissue, and impaired bridging of the defect by 6 weeks postoperative. Although mice in the LPS-treated group exhibited decreased activity and lethargy compared with the Control group for 1 to 2 days after surgery, none of the mice experienced serious complications and mortality was comparable (four per group). At 1 week postoperative, 2 hours after the last injection, serum TNF- $\alpha$ was $44 \pm 23 \mathrm{pg} /$ $\mathrm{mL}$ in Control mice injected with PBS and $254 \pm 152 \mathrm{pg} /$ $\mathrm{mL}$ in LPS-injected mice (95\% CI, 93-326 pg/mL; $\mathrm{p}<$ 0.001). MicroCT scans of the mid-sagittal region of defects showed better healing of the defect in Control mice (Fig. 1A-C) compared with LPS-treated mice at the same times (Fig. 1D-F). Bone repair was initiated at the proximal pole by 1 week postoperative in Control mice but was not visible until 2 weeks postoperative in LPS-injected mice. By 6 weeks postoperative the gap was bridged (Fig. 1C) in the majority of Control mice whereas a gap remained in the majority of LPS-treated mice (Fig. 1F). Distal bone formation (Fig. 1G) was evident in one of 


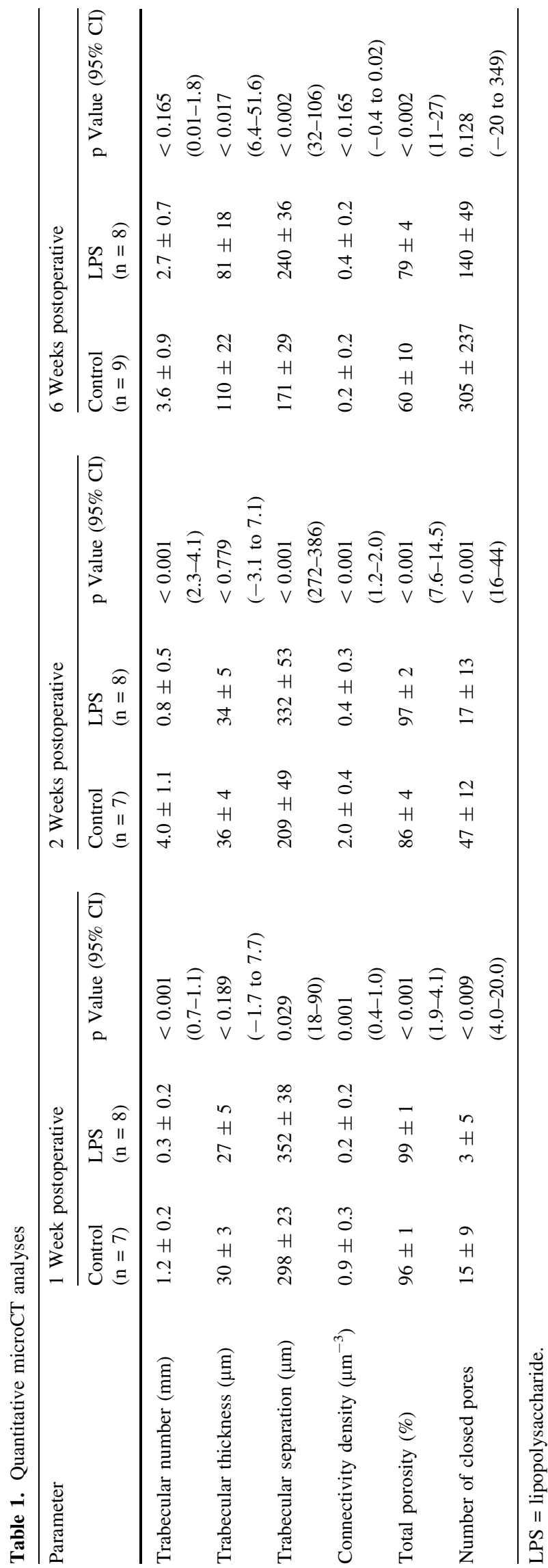

seven (14\%) Control mice at 1 week postoperative, five of seven $(71 \%)$ at 2 weeks, and eight of nine (89\%) at 6 weeks postoperative, compared with zero of seven at 1 week, one of seven (13\%) at 2 weeks (odds ratio [OR], 0.133; 95\% CI, 0.014-1.318; $\mathrm{p}=0.020)$, and three of eight $(38 \%)$ at 6 weeks (OR, 0.075; 95\% CI, 0.006-0.936; p = 0.027) in LPS-treated mice. Quantitative data for bridging of the gap (Fig. 1H) showed three of seven $(43 \%)$ bones bridged at 2 weeks in the Control group and zero of eight in the LPStreated group. By 6 weeks postoperative bridging had occurred in seven of nine (78\%) mice in the Control group and one of eight (13\%) in the LPS-treated group (OR, 0.04; 95\% CI, 0.003-0.560; $p=0.007)$. There was more bone (BV/TV) in the femoral medulla (Fig. 1I, J) of Control mice compared with LPS-treated mice at 1 week $(6.1 \% \pm$ $1.4 \%$ vs $0.9 \% \pm 0.3 \% ; 95 \%$ CI, $4.1 \%-6.3 \% ; \mathrm{p}<0.001)$ and 2 weeks $(17.2 \% \pm 4.5 \%$ vs $6.1 \% \pm 2.7 \% ; 95 \% \mathrm{CI}$, $6.8 \%-15.0 \% ; \mathrm{p}<0.001)$ postoperative, but there was no difference at 6 weeks $(14.6 \% \pm 6.8 \%$ vs $15.2 \% \pm 8.6 \%$; $95 \% \mathrm{CI},-9.3 \%$ to $8.3 \% ; \mathrm{p}=1.000)$ postoperative. In a similar manner BV/TV in the cortex (Fig $1 \mathrm{~K}, \mathrm{~L}$ ) was higher in Control than in LPS-injected mice at 1 week $(3.6 \% \pm 0.6 \%$ vs $0.8 \% \pm 0.7 \%$; $95 \%$ CI, $2.0 \%-3.5 \%$; $\mathrm{p}<$ $0.001)$ and 2 weeks $(14.0 \% \pm 3.5 \%$ vs $2.9 \% \pm 2.1 \% ; 95 \%$ CI, 7.9\%-14.3\%; $\mathrm{p}<0.001)$, which was maintained at 6 weeks $(39.0 \% \pm 10.0 \%$ vs $21.5 \% \pm 4.2 \%$; $95 \%$ CI, $9.7 \%$ $26.3 \% ; \mathrm{p}=0.002)$ postoperative. Additional data describing the microarchitecture of bone in the window defect show that Control mice had more trabeculae (trabecular number) that were better connected to one another (connectivity density) with lower porosity and more osteocyte lacunae (closed pores) in initial woven bone occupying the window defect compared with mice treated with LPS at 1 and 2 weeks postoperative (Table 1). At 6 weeks postoperative trabeculae were thicker with fewer spaces in Control compared with LPS-treated bone (Table 1).

\section{Vascularization, Cellularity, Anabolism, and Catabolism}

LPS-induced systemic inflammation was associated with a reduction in the number of CD34-positive vascular endothelial cells and masts cells in repair tissue at 1 week postoperative, reduced ALP and TRAP activity, and an increase F4/80 staining of all macrophages relative to Arg1 stained M2 macrophages. Sections of decalcified bone harvested at the mid-sagittal region of the femurs and stained with hematoxylin and eosin were used to evaluate the morphologic features of repair tissue (Fig. 2). At 1 week postoperative condensed connective tissue occupied the marrow cavity adjacent to the bone defect in Control (Fig. 2G) and LPS-treated (Fig. 2H) mice. At 2 weeks 


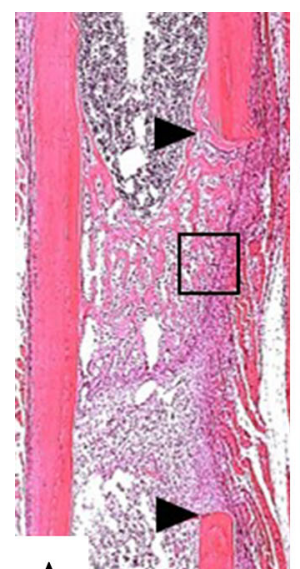

A
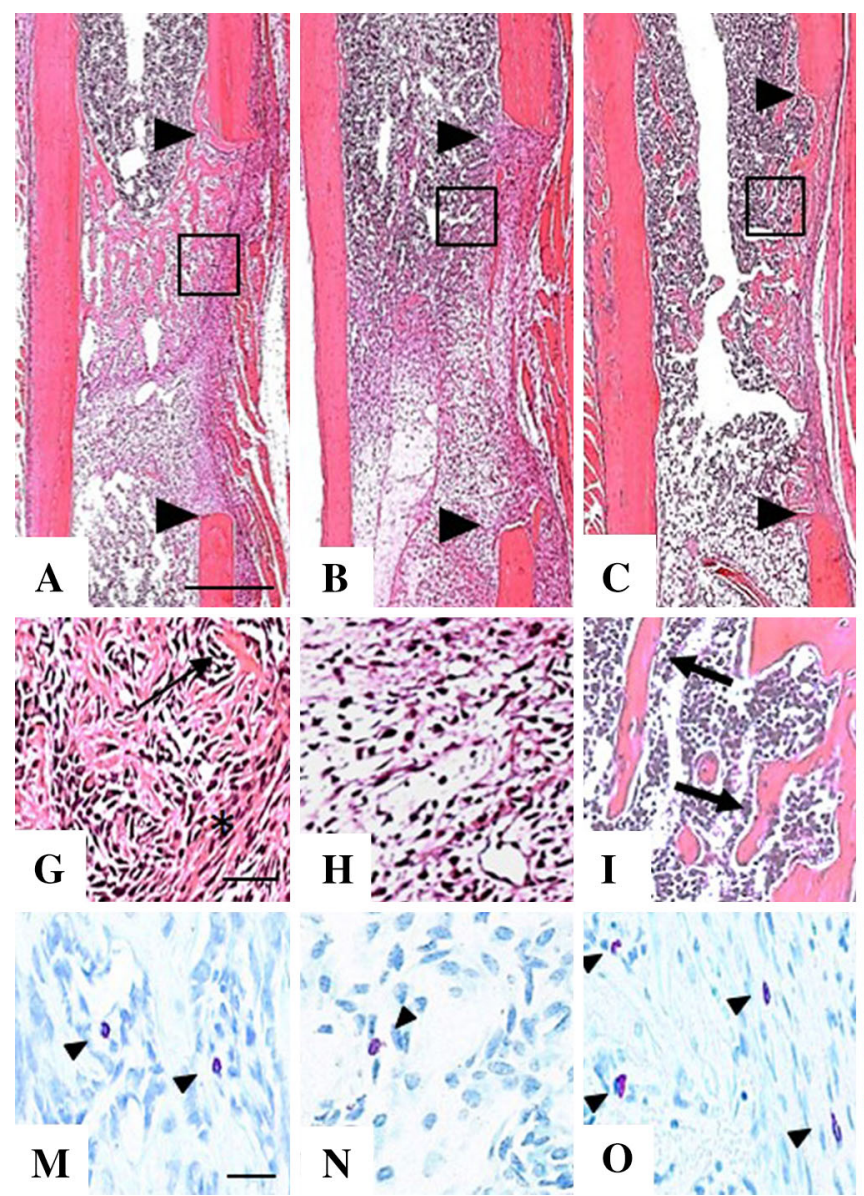

Fig. 2A-R Representative images of $5-\mu \mathrm{m}$ sections from the midsagittal region of decalcified, paraffin embedded femurs were stained with hematoxylin and eosin and adjacent sections stained with acidified toluidine blue to identify purple granular mast cells. Lowmagnification images of hematoxylin and eosin-stained sections at 1 week for (A) Control and (B) lipopolysaccharide (LPS)-treated mice, 2 weeks for (C) Control and (D) LPS-treated mice, and 6 weeks after surgery for (E) Control and (F) LPS-treated mice show the margins of the defect (arrowheads) and the region of tissue (box) where highmagnification images were taken. At 1 week postoperative (G) Control mice had newly formed bone (arrow) on the endosteal side, and dense, fibrous tissue (asterisk) on the periosteal side of the defect, while (H) LPS-treated mice had only condensed mesenchyme. At 2 weeks postoperative (I) Control femurs showed a clear pattern of

postoperative trabeculae of woven bone were seen in Control (Fig. 2I) femurs whereas islands of bone in condensed connective tissue were seen in LPS-treated bones (Fig. 2J). By 6 weeks postoperative the bone bridging the defect resembled that of the intact cortex in Control mice (Fig. 2K), whereas LPS-treated mice exhibited residual trabeculae in the medullary cavity and gaps filled with fibrous tissue (Fig. 2L). Mast cells, whose granules stain purple with acidified toluidine blue, were seen primarily in loose connective tissue at 1 week (Fig. $2 \mathrm{M}, \mathrm{N}$ ), around sinusoids and bordering new bone at 2 weeks (Fig. 2O, P),
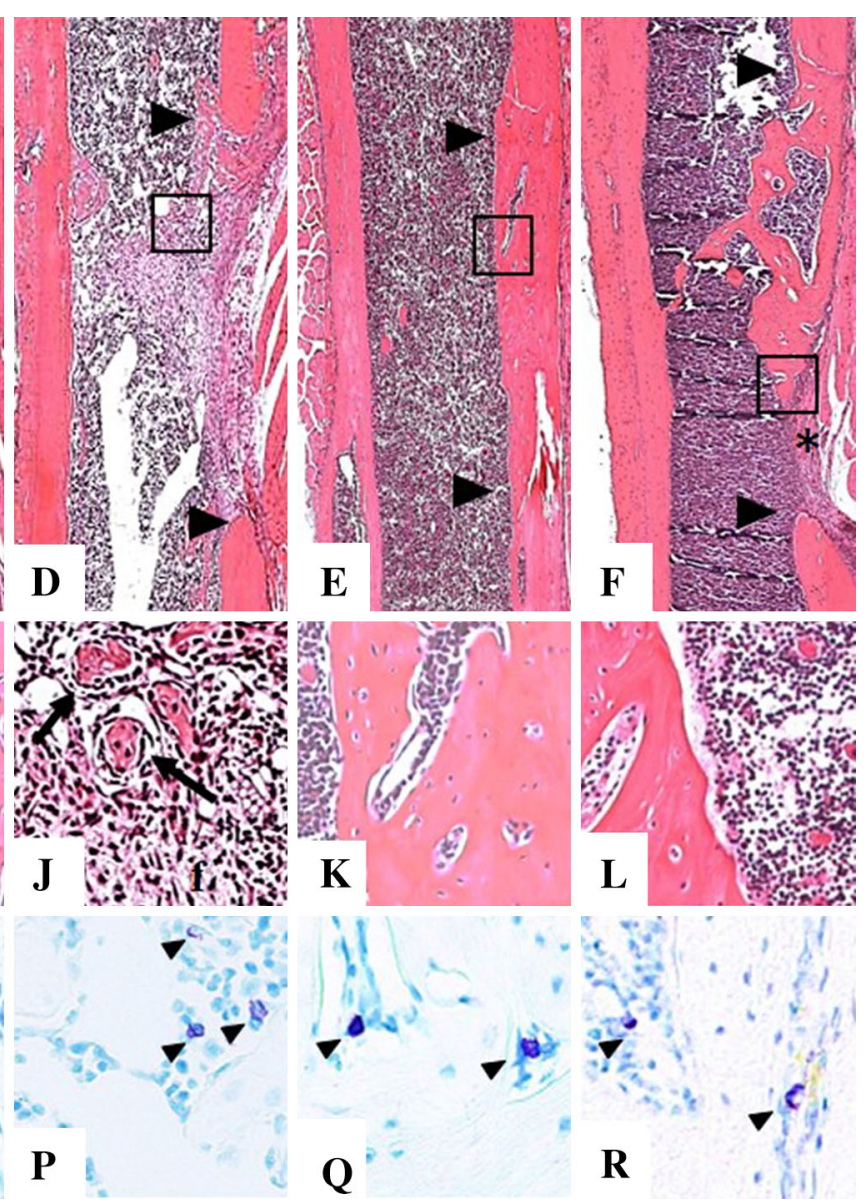

bone trabeculae (arrows) surrounded by marrow, and in the defect of (J) LPS-treated mice, disorganized islands of bone (arrows) in mesenchyme are seen. At 6 weeks postoperative the trabecular bone matures into woven bone with a normal cortical shape in the $(\mathbf{K})$ Control group whereas in the (L) LPS-treated group there are large lacunae in the cortical bone and fibrous tissue remaining in the gap (asterisk in Illustration F). Mast cells (arrowheads) appear more numerous in (M) Control than in (N) LPS-treated bones at 1 week postoperative, whereas equivalent numbers were seen at 2 weeks after surgery in the (O) Control and (P) LPS-treated groups. By 6 weeks postoperative mast cell numbers and location were still similar in $(\mathbf{Q})$ Control and (R) LPS-treated mice. Scale bars $=500 \mu \mathrm{m}$ (A-F), $50 \mu \mathrm{m}$ (G-L) and $20 \mu \mathrm{m}(\mathrm{M}-\mathrm{R})$.

and in marrow spaces at 6 weeks postoperative (Fig. 2Q, $\mathrm{R}$ ) in both groups. Quantification of the purple granular cells revealed more mast cells in Control than in LPStreated mice at 1 week postoperative, but with no differences between the groups thereafter (Table 2).

Quantitative data for histochemical (TRAP, ALP) and immunochemical (CD34, F4/80, Arg-1) staining at 1, 2, and 6 weeks postoperative showed differences between the Control and LPS-treated mice in all parameters at 1 week postoperative but in none of the parameters at 6 weeks postoperative (Table 2). More staining for TRAP (Fig. 3A, 
Table 2. Quantitative analyses of cellular composition

\begin{tabular}{|c|c|c|c|c|c|c|c|c|c|}
\hline \multirow[t]{2}{*}{ Stain and target } & \multicolumn{3}{|c|}{1 Week postoperative } & \multicolumn{3}{|c|}{2 Weeks postoperative } & \multicolumn{3}{|c|}{6 Weeks postoperative } \\
\hline & $\begin{array}{l}\text { Control } \\
(n=7)\end{array}$ & $\begin{array}{l}\text { LPS } \\
(\mathrm{n}=8)\end{array}$ & $\begin{array}{l}\mathrm{p} \text { Value } \\
(95 \% \mathrm{CI})\end{array}$ & $\begin{array}{l}\text { Control } \\
(n=7)\end{array}$ & $\begin{array}{l}\text { LPS } \\
(n=8)\end{array}$ & $\begin{array}{l}\mathrm{p} \text { Value } \\
(95 \% \mathrm{CI})\end{array}$ & $\begin{array}{l}\text { Control } \\
(n=9)\end{array}$ & $\begin{array}{l}\text { LPS } \\
(n=8)\end{array}$ & $\begin{array}{l}\mathrm{p} \text { Value } \\
(95 \% \mathrm{CI})\end{array}$ \\
\hline $\begin{array}{l}\text { Acid TB: mast cells/ } \\
\mathrm{mm}^{2}\end{array}$ & $2.1 \pm 1.0$ & $0.5 \pm 0.6$ & $\begin{array}{l}0.009 \\
(0.6-2.5)\end{array}$ & $8.4 \pm 5.2$ & $9.8 \pm 5.8$ & $\begin{array}{l}0.613 \\
(7.6-4.8)\end{array}$ & $9.4 \pm 9.2$ & $10.0 \pm 6.2$ & $\begin{array}{l}1.000 \\
(10.9-17.8)\end{array}$ \\
\hline VEGF: angiogenesis & $0.5 \pm 0.3$ & $0.5 \pm 0.3$ & $\begin{array}{l}1.000 \\
(-3.4 \text { to } 3.4)\end{array}$ & $1.5 \pm 1.5$ & $0.9 \pm 0.8$ & $\begin{array}{l}0.818 \\
(0.7-1.9)\end{array}$ & $1.7 \pm 0.3$ & $1.8 \pm 0.8$ & $\begin{array}{l}1.000 \\
(0.8-0.6)\end{array}$ \\
\hline $\begin{array}{l}\text { CD34: vascular } \\
\text { endothelium }\end{array}$ & $5.0 \pm 1.1$ & $2.3 \pm 0.9$ & $\begin{array}{l}0.001 \\
(1.6-3.8)\end{array}$ & $3.4 \pm 0.9$ & $1.1 \pm 0.6$ & $\begin{array}{l}<0.001 \\
(1.5-3.1)\end{array}$ & $0.5 \pm 0.1$ & $0.4 \pm 0.2$ & $\begin{array}{l}0.286 \\
(0.1-0.3)\end{array}$ \\
\hline $\begin{array}{c}\mathrm{F} 4 / 80: \mathrm{M} 1 / \mathrm{M} 2 \\
\text { macrophage }\end{array}$ & $7.4 \pm 3.4$ & $16.5 \pm 4.6$ & $\begin{array}{l}<0.001 \\
(4.5-13.7)\end{array}$ & $6.8 \pm 1.7$ & $13.0 \pm 2.6$ & $\begin{array}{l}<0.001 \\
(3.7-8.7)\end{array}$ & $2.5 \pm 0.5$ & $2.6 \pm 1.1$ & $\begin{array}{l}0.413 \\
(1.1-0.9)\end{array}$ \\
\hline Arg-1: M2 macrophage & $1.2 \pm 0.3$ & $1.6 \pm 0.5$ & $\begin{array}{l}0.072 \\
(0.9-0.1)\end{array}$ & $0.6 \pm 0.4$ & $4.5 \pm 3.2$ & $\begin{array}{l}<0.001 \\
(1.3-6.5)\end{array}$ & $0.7 \pm 0.2$ & $0.8 \pm 0.3$ & $\begin{array}{l}0.413 \\
(0.4-0.2)\end{array}$ \\
\hline Cathepsin K: collagen 1 & $0.07 \pm 0.02$ & $0.06 \pm 0.02$ & $\begin{array}{l}0.121 \\
(0.01-0.03)\end{array}$ & $0.9 \pm 0.3$ & $0.3 \pm 0.2$ & $\begin{array}{l}<0.001 \\
(0.4-0.9)\end{array}$ & $0.1 \pm 0.1$ & $0.2 \pm 0.1$ & $\begin{array}{l}0.730 \\
(0.2-0.1)\end{array}$ \\
\hline $\begin{array}{l}\text { TRAP: OC and fibrous } \\
\text { marrow }\end{array}$ & $1.6 \pm 0.8$ & $0.7 \pm 0.2$ & $\begin{array}{l}0.004 \\
(0.3-1.5)\end{array}$ & $7.2 \pm 4.0$ & $3.3 \pm 4.7$ & $\begin{array}{l}0.014 \\
(2.7-9.0)\end{array}$ & $0.6 \pm 0.3$ & $0.7 \pm 0.7$ & $\begin{array}{l}0.413 \\
(0.2-0.1)\end{array}$ \\
\hline $\begin{array}{l}\text { TRAP: against new } \\
\text { bone only }\end{array}$ & $0.05 \pm 0.03$ & $1.3 \pm 2.6$ & $\begin{array}{l}0.002 \\
(0.9-3.4)\end{array}$ & $0.4 \pm 0.3$ & $0.8 \pm 0.7$ & $\begin{array}{l}1.000 \\
(1.0-0.2)\end{array}$ & $0.01 \pm 0.01$ & $0.04 \pm 0.03$ & $\begin{array}{l}0.286 \\
(0.1-0.5)\end{array}$ \\
\hline ALP: OB enzyme & $24.7 \pm 11.0$ & $3.9 \pm 3.4$ & $\begin{array}{l}<0.001 \\
(12.0-29.6)\end{array}$ & $6.1 \pm 3.2$ & $1.9 \pm 0.9$ & $\begin{array}{l}0.025 \\
(1.7-6.7)\end{array}$ & $0.9 \pm 0.3$ & $1.3 \pm 0.5$ & $\begin{array}{l}0.190 \\
(0.9-0.1)\end{array}$ \\
\hline
\end{tabular}

Acid TB = acidified toluidine blue; $\mathrm{VEGF}=$ vascular endothelial growth factor; TRAP $=$ tartrate resistant acid phosphatase; ALP $=$ alkaline phosphatase; $\mathrm{OC}=$ osteoclast; $\mathrm{OB}=$ osteoblast.

B), ALP (Fig. 3C, D), and CD34 (Fig. 3E, F) was seen in Control compared with LPS-treated mice at 2 weeks postoperative, whereas F4/80 (Fig. 3G, H) and Arg-1 (Fig. 3I, J) staining were lower in Control mice. The absolute activity of TRAP positive catabolic cells was higher in the Control mice compared with the LPS-treated mice at 1 week $(1.6 \% \pm 0.8 \% ; 95 \% \mathrm{CI}, 0.3 \%-1.5 \% ; \mathrm{p}=$ $0.004)$ and 2 weeks $(7.2 \% \pm 4.0 \%$ vs $3.3 \% \pm 4.7 \% ; 95 \%$ CI, $2.7 \%-9.0 \%$; $\mathrm{p}=0.014)$ postoperative. When normalized to new bone surfaces there was relatively higher activity in the LPS-treated mice at 1 week postoperative $(1.3 \pm 2.6$ vs $0.05 \pm 0.03 ; 95 \%$ CI, 0.9-3.4; $\mathrm{p}=0.002)$ but with no differences thereafter (Table 2).

\section{Discussion}

Current approaches to the treatment of orthopaedic, maxillofacial, and dental injuries often are complicated by the limited regenerative capacity of bone, which results in delayed healing and malunions. Recent studies suggest that modulation of the immune system offers a noninvasive option to enhance bone repair [42, 44, 48]. Immune cells and inflammatory cytokines have been found to have a major influence on the success of cell transplantation-based therapies like tissue-engineered scaffolds seeded with MSCs [44]. Despite progress in the field of osteoimmunology in general, the interactions between cells of the immune system and those involved in bone repair remain underexplored. Our study builds on our previous work that investigated the effect of mast-cell deficiency in KitW-sh mice on the inflammatory phase of bone repair using a mouse model of a mechanically stable femoral defect [6]. The current study used the same preclinical model to investigate the effect of systemic inflammation, evidenced by elevated circulating $\mathrm{TNF} \alpha$, on bone repair. The data indicate that LPS-induced systemic inflammation reduced the amount (BV/TV) and impaired the quality (trabecular separation and porosity) of bone regenerated at 6 weeks postoperative in skeletally mature mice. At 2 weeks postoperative the effects were associated with reduced expression of CD34 (marker for vascular endothelial cells), reduced ALP (osteoblasts) and TRAP (osteoclasts), and increased expression of F4/80 and arginase-1, which was indicative of a relative increase in catabolic macrophages.

We acknowledge several limitations to our study. First, the results are not directly applicable to humans as a murine model was used. However, the immune response to LPS-induced systemic inflammation in mice has been well characterized in rodents $[1,12,23,27,49]$, and shown to be 

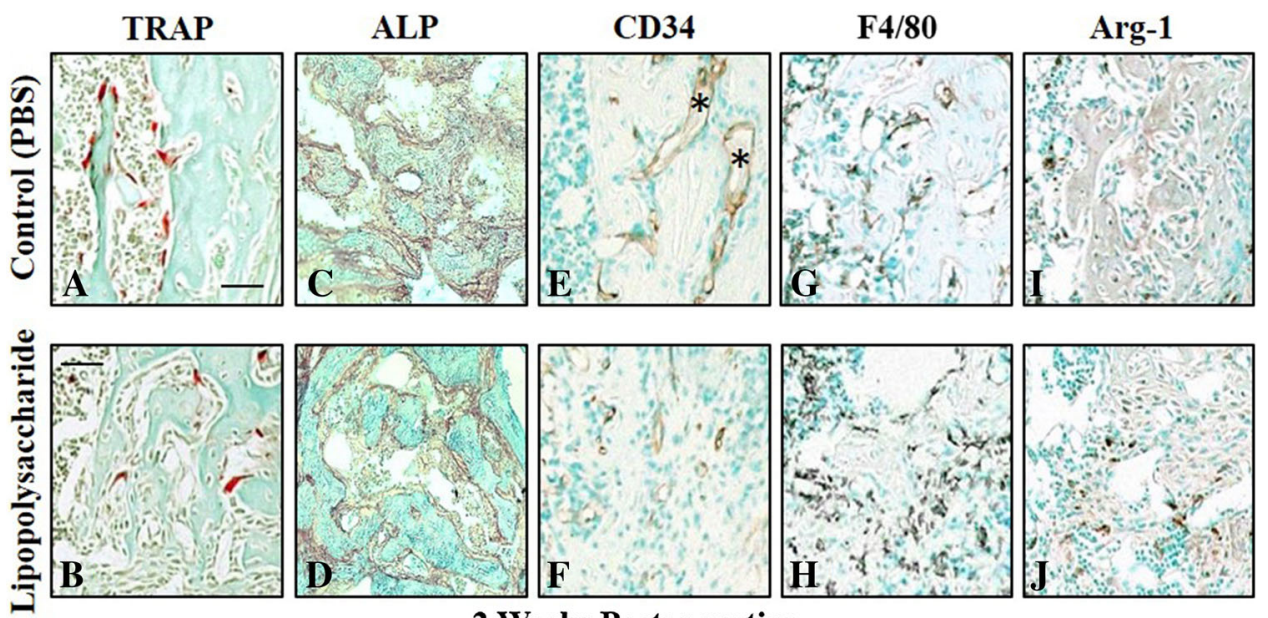

2 Weeks Postoperative

Fig. 3A-J Mid-sagittal sections were harvested from decalcified, paraffin-embedded femurs of Control and lipopolysaccharide (LPS)treated mice euthanized at 2 weeks postoperative and adjacent sections stained for quantitative analyses of cell composition. Tartrate resistant acid phosphatase (TRAP)-positive osteoclasts (red) adjacent to bone spicules (green) were more numerous in bones harvested from (A) Control compared with (B) LPS-treated mouse femurs. Alkaline phosphatase (ALP)-positive osteoblasts also were more numerous in (C) Control compared with (D) LPS-treated mouse femurs. (E) Newly

comparable to that seen in humans [8]. LPS introduced into the intraperitoneal cavity enters the systemic circulation via the portal vein and activates the immune system [5], which was confirmed by monitoring serum TNF $\alpha$ in our study. This mimics the clinical situation in cases of severe trauma when the gut barrier is impaired and gram negative bacteria containing LPS enter the blood stream [11, 41]. Second, we focused mainly on the cells that have been shown to play an important role in the inflammatory, regenerative, and remodeling phases (1-6 weeks postoperative) of the repair process. Bone repair in femoral defects proceeds from proximal (3-7 days postinjury) to distal (7-14 days postinjury). The delay in initiation of repair at the proximal and distal ends of the defect in LPS-treated mice was most likely a consequence of impaired revascularization, particularly at the distal pole which is less well vascularized in the first place [7]. Additional experiments analyzing the cells and their interactions during the first few days of healing are warranted but were beyond the scope of this work. Third, although histologic and immunohistochemical analyses provide relevant information regarding the quantity and location of cells and enzymes, additional methods such as fluorescence-activated cell sorting will be required to confirm the results. Fourth, coculture experiments with the cells involved in a controlled ex vivo environment will be required to uncover the molecular pathways responsible for the abnormalities. formed blood vessels (asterisk) lined with CD34-positive vascular endothelial cells were more numerous in Control femurs than in those from (F) LPS-treated mice. The total number of F4/80-positive macrophages was lower in (G) Control bone compared with that from (H) LPS-treated mice. A similar pattern was seen with arginase-1 positive M2 macrophages, which were fewer in (I) Control femurs than in femurs from (J) LPS-treated mice. Scale bar represents $50 \mu \mathrm{m}$ for all images.

In a similar study performed in rats, femoral fractures were fixed with an intrafemoral nail, which provides limited stability when used in clinical practice, and resulted in secondary bone healing [40]. Administration of LPS for 7 days after surgery during the inflammatory stage resulted in impaired healing of the fractures at 6 weeks postoperative, as indicated by reductions in bone mineral content and density and decreased biomechanical strength at the fracture site. Although the animal model (rat vs mouse), mechanism of bone repair (secondary vs primary), and outcome measures (bone mineral density and biomechanical strength vs quantitative microCT and histopathology) in that study differed from our study, the conclusion was the same. LPS-induced systemic inflammation resulted in decreased quantity and impaired quality of regenerated bone. These observations emphasize not only the long-term deleterious effect of systemic inflammation during the early phase of bone repair but also the importance of defining the cellular microenvironment of healing bone.

To further explore the cellular mechanisms underlying impaired bone healing in the LPS-treated mice, we performed histochemical and immunochemical analyses to identify cells involved in the processes of revascularization (CD34), removal of debris (F4/80), repair (ALP), and remodeling (TRAP). CD34, ALP, and TRAP activity were reduced and F4/80 activity increased in the LPS-treated mice at 2 weeks postoperative, but no difference was seen 
in these parameters between the Control and LPS-treated mice at 6 weeks postoperative. This could reflect the limited duration of the LPS treatment to the first week of healing. Importantly, it indicates that early disruption of cellular activity in the bone-healing microenvironment will have a lasting, deleterious effect on the repair process. Osteoclasts are a major constituent of the bone-repair process that share a common circulating precursor with monocytes and macrophages [26]. In chronic, systemic inflammatory conditions like rheumatoid arthritis, elevated levels of proinflammatory mediators increase osteoclast activity and promote bone loss [39]. Although the absolute activity of osteoclasts was lower in the LPS-treated mice compared with the Control mice, their relative activity when compared with the surface of new bone was increased. The relative TRAP activity is the more important value in this case [30], as osteoclasts are found only adjacent to new bone and there was less new bone in the LPS-treated mice. ALP is a recognized marker for osteoblasts and other cell types in the bone microenvironment including hypertrophic chondrocytes, MSCs, and vascular pericytes $[17,20]$. The reduction in ALP at 1 and 2 weeks postoperative in LPS-treated mice was most likely responsible for the reduction in bone volume observed by microCT analysis. A plausible explanation would be the presence of LPS-induced systemic inflammation and elevated circulating TNF- $\alpha$, which has been reported to inhibit the differentiation of MSCs in bone-forming osteoblasts by suppressing Cbfa1 [19]. Moreover, resolution of the inflammatory phase of bone healing is proposed to be necessary for effective osteoblast function [33]. The concurrent expression of peak levels of ALP-positive osteogenic and CD34 vascular endothelial cells at 1 week postoperative in the condensing mesenchyme at the site of repair supports the hypothesis that there is crosstalk between the lineages destined to become bone and vascular tissue [4].

In fractures, revascularization of the injured tissue is controlled mainly by VEGF [21, 24, 31]. Using a murine model of fracture repair and secondary bone healing it was shown that systemic administration of the antiinflammatory indomethacin enhanced revascularization of the fracture callus at 7 days postoperative, but bone healing was impaired at 28 days postoperative [31]. Others used an ovine femoral osteotomy model in which mechanical instability led to an increase in inflammatory cells in and adjacent to the defect, accompanied by a reduction in angiogenic factors, including VEGF [43]. In the current study using a mechanically stable defect in the mouse femur, a reduction in vascularization (CD34 immunoreactivity) was not accompanied by any change in VEGF immunoreactivity in LPS-treated mice at 7 and 14 days postoperative. The different species and/or models of bone repair in previous work might explain the differences in VEGF expression. Alternatively, angiopoietin, a protein expressed during the early phase of bone healing, could have been altered in the LPS-induced mice to result in a reduction in revascularization [28].

Effective revascularization and bone repair also depend on a physiologic balance between M1 and M2 macrophages [2, 47]. The F4/80 antibody recognizes inflammatory M1 and proangiogenic, tissue repair-inducing M2 subtypes whereas the Arg-1 antibody recognizes only M2 macrophages. F4/80 immunoreactivity was increased in LPS-treated mice at 7 and 14 days postoperative while Arg-1 immunoreactivity did not become elevated until 14 days postoperative. LPS induces M1 macrophage differentiation and activity but has little effect on M2 macrophages [32], which indicated increased F4/80 immunoreactivity at 7 days postoperative was indicative of a relative increase in M1 over M2 macrophages in LPStreated mice. This relative increase in M1 over M2 macrophages during the first week of healing could have had a negative effect on bone repair at 6 weeks postoperative. The increase in Arg-1 immunoreactivity in LPS-treated mice at 14 days postoperative localized almost exclusively to the fibrous tissue in the window defect, which was much more abundant in these animals compared with the control animals and most likely reflected the profibrotic effect of the M2a macrophage subset [3, 34-36]. Similar macrophage-induced increases in fibrous tissue formation leading to defective healing of skin wounds have been associated with LPS-induced systemic inflammation [37]. In addition to macrophages, mast cells have been implicated in the immune response to trauma in a mouse model of acute systemic inflammation [9]. The systemic inflammatory response and end organ (liver, lung) damage 6 hours after being subjected to hemorrhagic shock and femoral fracture were less severe in mast cell-deficient KitW-sh mice compared with wild type mice. Cai et al. [9] concluded from their data that mast cells play a key role in the systemic inflammatory response. In previous work we characterized healing of the femoral bone defect used in the current study in mast cell-deficient KitW-sh mice [6]. In both studies we showed impaired revascularization using CD34 immunoreactivity at 7 and 14 days postoperative. In contrast, F4/80 immunoreactivity was decreased in the previous study and increased in the current study. The results imply that mast cells and macrophages interact with one another during the inflammatory phase of bone repair.

The current in vivo mouse study shows that transient LPS-induced systemic inflammation compromised revascularization and osseous repair resulting in defective healing of a cortical window defect. Short-term alterations in the activity of vascular endothelial cells, macrophages, osteoclasts, and osteoblasts during the first 2 weeks of 
healing had long-term deleterious effects on bone repair evaluated at 6 weeks postoperative. Based on our study, future clinical investigations might evaluate local administration of VEGF into the fracture callus to stimulate revascularization, or transplantation of stem cells to enhance bone turnover [44]. Our results also emphasize the potential for immunotherapy aimed at shifting the balance to favor M2 over M1 macrophages during the early inflammatory phase as a potential therapeutic intervention to improve bone healing. Definition of the molecular pathways whereby cells in the bone healing microenvironment interact with one another during the repair process awaits future studies focused on bone marrow-derived cells in a controlled ex vivo environment.

Acknowledgments Funding was provided by FRQ-S (Grant No. 30874, Summer studentship), Faculty of Medicine, McGill University (Strauss Fellowship, Excellence graduate fellowship, Department of Experimental Surgery, MIDAS studentship award, RI-MUHC studentship award), CIHR (MENTOR program), NCE-MITACS Accelerate (studentship award), FRSQ (studentship award), King Saud University, Riyadh, Saudi Arabia and University of Jeddah, Saudi Arabia.

\section{References}

1. Abou-Khalil R, Yang F, Mortreux M, Lieu S, Yu YY, Wurmser M, Pereira C, Relaix F, Miclau T, Marcucio RS, Colnot C. Delayed bone regeneration is linked to chronic inflammation in murine muscular dystrophy. J Bone MinerRes. 2014;29:304-315.

2. Alexander KA, Chang MK, Maylin ER, Kohler T, Muller R, Wu AC, Van Rooijen N, Sweet MJ, Hume DA, Raggatt LJ, Pettit AR. Osteal macrophages promote in vivo intramembranous bone healing in a mouse tibial injury model. J Bone Miner Res. 2011;26:1517-1532.

3. Anders HJ, Ryu M. Renal microenvironments and macrophage phenotypes determine progression or resolution of renal inflammation and fibrosis. Kidney Int. 2011;80:915-925.

4. Armulik A, Genové G, Betsholtz C. Pericytes: developmental, physiological, and pathological perspectives, problems, and promises. Dev Cell. 2011;21:193-215.

5. Asari Y, Majima M, Sugimoto K, Katori M, Ohwada T. Release site of TNF alpha after intravenous and intraperitoneal injection of LPS from Escherichia coli in rats. Shock. 1996;5:208-212.

6. Behrends DA, Cheng L, Sullivan MB, Wang MH, Roby GB, Zayed N, Gao C, Henderson JE, Martineau PA. Defective bone repair in mast cell deficient mice with c-Kit loss of function. Eur Cell Mater. 2014;28:209-221; discussion 221-222.

7. Boerckel JD, Uhrig BA, Willett NJ, Huebsch N, Guldberg RE. Mechanical regulation of vascular growth and tissue regeneration in vivo. Proc Natl Acad Sci U S A. 2011;108:674-680.

8. Bubalo N, Nguyen P, Nguyen T, Abramson T, Wilkinson K. Characterization of the immune response in male and female mice following lipopolysaccharide-induced systemic inflammation. FASEB J. 2014;28(suppl 1096):10. Available at: http:// www.fasebj.org/content/28/1_Supplement/1096.10.short. Accessed October 25, 2016.

9. Cai C, Cao Z, Loughran PA, Kim S, Darwiche S, Korff S, Billiar TR. Mast cells play a critical role in the systemic inflammatory response and end-organ injury resulting from trauma. J Am Coll Surg. 2011;213:604-615.
10. Champagne CM, Takebe J, Offenbacher S, Cooper LF. Macrophage cell lines produce osteoinductive signals that include bone morphogenetic protein-2. Bone. 2002;30:26-31.

11. Chang JX, Chen S, Ma LP, Jiang LY, Chen JW, Chang RM, Wen LQ, Wu W, Jiang ZP, Huang ZT. Functional and morphological changes of the gut barrier during the restitution process after hemorrhagic shock. World J Gastroenterol. 2005;11:5485-5491.

12. Chen LW, Egan L, Li ZW, Greten FR, Kagnoff MF, Karin M. The two faces of IKK and NF-kappaB inhibition: prevention of systemic inflammation but increased local injury following intestinal ischemia-reperfusion. Nat Med. 2003;9:575-581.

13. Claes L, Recknagel S, Ignatius A. Fracture healing under healthy and inflammatory conditions. Nat Rev Rheumatol. 2012;8:133143.

14. Dimitriou R, Jones E, McGonagle D, Giannoudis PV. Bone regeneration: current concepts and future directions. BMC Med. 2011;9:66.

15. Einhorn TA, Gerstenfeld LC. Fracture healing: mechanisms and interventions. Nat Rev Rheumatol. 2015;11:45-54.

16. Gao C, Harvey EJ, Chua M, Chen BP, Jiang F, Liu Y, Li A, Wang $\mathrm{H}$, Henderson JE. MSC-seeded dense collagen scaffolds with a bolus dose of VEGF promote healing of large bone defects. Eur Cell Mater. 2013;26:195-207; discussion 207.

17. Geevarghese A, Herman IM. Pericyte-endothelial crosstalk: implications and opportunities for advanced cellular therapies. Transl Res. 2014;163:296-306.

18. Gerstenfeld LC, Cullinane DM, Barnes GL, Graves DT, Einhorn TA. Fracture healing as a post-natal developmental process: molecular, spatial, and temporal aspects of its regulation. J Cell Biochem. 2003;88:873-884.

19. Gilbert L, He X, Farmer P, Rubin J, Drissi H, van Wijnen AJ, Lian JB, Stein GS, Nanes MS. Expression of the osteoblast differentiation factor RUNX2 (Cbfa1/AML3/Pebp2alphaA) is inhibited by tumor necrosis factor-alpha. $J$ Biol Chem. 2002;277:2695-2701.

20. Giuliani N, Lisignoli G, Magnani M, Racano C, Bolzoni M, Dalla Palma B, Spolzino A, Manferdini C, Abati C, Toscani D. New insights into osteogenic and chondrogenic differentiation of human bone marrow mesenchymal stem cells and their potential clinical applications for bone regeneration in pediatric orthopaedics. Stem Cells Int. 2013;2013:312501.

21. Goerke SM, Obermeyer J, Plaha J, Stark GB, Finkenzeller G. Endothelial progenitor cells from peripheral blood support bone regeneration by provoking an angiogenic response. Microvasc Res. 2015;98:40-47.

22. Howard M, Muchamuel T, Andrade S, Menon S. Interleukin 10 protects mice from lethal endotoxemia. $J$ Exp Med. 1993; 177:1205-1208.

23. Jiang M, Xu X, Bi Y, Xu J, Qin C, Han M. Systemic inflammation promotes lung metastasis via E-selectin upregulation in mouse breast cancer model. Cancer Biol Ther. 2014;15:789-796.

24. Kanczler JM, Oreffo RO. Osteogenesis and angiogenesis: the potential for engineering bone. Eur Cell Mater. 2008;15:100114.

25. Kolar P, Schmidt-Bleek K, Schell H, Gaber T, Toben D, Schmidmaier G, Perka C, Buttgereit F, Duda GN. The early fracture hematoma and its potential role in fracture healing. Tissue Eng Part B Rev. 2010;16:427-434.

26. Kotani M, Kikuta J, Klauschen F, Chino T, Kobayashi Y, Yasuda H, Tamai K, Miyawaki A, Kanagawa O, Tomura M, Ishii M. Systemic circulation and bone recruitment of osteoclast precursors tracked by using fluorescent imaging techniques. J Immunol. 2013;190:605-612.

27. Kovtun A, Bergdolt S, Wiegner R, Radermacher P, Huber-Lang $\mathrm{M}$, Ignatius A. The crucial role of neutrophil granulocytes in bone fracture healing. Eur Cell Mater. 2016;32:152-162. 
28. Lehmann W, Edgar CM, Wang K, Cho TJ, Barnes GL, Kakar S, Graves DT, Rueger JM, Gerstenfeld LC, Einhorn TA. Tumor necrosis factor alpha (TNF-alpha) coordinately regulates the expression of specific matrix metalloproteinases (MMPS) and angiogenic factors during fracture healing. Bone. 2005;36:300310 .

29. Lienau J, Schmidt-Bleek K, Peters A, Haschke F, Duda GN, Perka C, Bail HJ, Schutze N, Jakob F, Schell H. Differential regulation of blood vessel formation between standard and delayed bone healing. J Orthop Res. 2009;27:1133-1140.

30. Lips KS, Kneffel M, Willscheid F, Mathies FM, Kampschulte M, Hartmann S, Panzer I, Durselen L, Heiss C, Kauschke V. Altered ultrastructure, density and cathepsin $\mathrm{K}$ expression in bone of female muscarinic acetylcholine receptor M3 knockout mice. Int Immunopharmacol. 2015;29:201-207.

31. Lu C, Xing Z, Wang X, Mao J, Marcucio RS, Miclau T. Antiinflammatory treatment increases angiogenesis during early fracture healing. Arch Orthop Trauma Surg. 2012;132:12051213.

32. Martinez FO, Gordon S. The M1 and M2 paradigm of macrophage activation: time for reassessment. F1000Prime Rep. 2014;6:13.

33. Matzelle MM, Gallant MA, Condon KW, Walsh NC, Manning CA, Stein GS, Lian JB, Burr DB, Gravallese EM. Resolution of inflammation induces osteoblast function and regulates the Wnt signaling pathway. Arthritis Rheum. 2012;64:1540-1550.

34. Moore JP, Vinh A, Tuck KL, Sakkal S, Krishnan SM, Chan CT, Lieu M, Samuel CS, Diep H, Kemp-Harper BK, Tare M, Ricardo SD, Guzik TJ, Sobey CG, Drummond GR. M2 macrophage accumulation in the aortic wall during angiotensin II infusion in mice is associated with fibrosis, elastin loss, and elevated blood pressure. Am J Physiol Heart Circ Physiol. 2015;309:H906H917.

35. Murray LA, Chen Q, Kramer MS, Hesson DP, Argentieri RL, Peng X, Gulati M, Homer RJ, Russell T, van Rooijen N, Elias JA, Hogaboam CM, Herzog EL. TGF-beta driven lung fibrosis is macrophage dependent and blocked by serum amyloid P. Int $J$ Biochem Cell Biol. 2011;43:154-162.

36. Murray PJ, Allen JE, Biswas SK, Fisher EA, Gilroy DW, Goerdt S, Gordon S, Hamilton JA, Ivashkiv LB, Lawrence T, Locati M, Mantovani A, Martinez FO, Mege JL, Mosser DM, Natoli G, Saeij JP, Schultze JL, Shirey KA, Sica A, Suttles J, Udalova I, van Ginderachter JA, Vogel SN, Wynn TA. Macrophage activation and polarization: nomenclature and experimental guidelines. Immunity. 2014;41:14-20.

37. Qi Y, Jiang D, Sindrilaru A, Stegemann A, Schatz S, Treiber N, Rojewski M, Schrezenmeier H, Vander Beken S, Wlaschek M, Bohm M, Seitz A, Scholz N, Durselen L, Brinckmann J, Ignatius
A, Scharffetter-Kochanek K. TSG-6 released from intradermally injected mesenchymal stem cells accelerates wound healing and reduces tissue fibrosis in murine full-thickness skin wounds. $J$ Invest Dermatol. 2014;134:526-537.

38. Recknagel S, Bindl R, Brochhausen C, Göckelmann M, Wehner $\mathrm{T}$, Schoengraf P, Huber-Lang M, Claes L, Ignatius A. Systemic inflammation induced by a thoracic trauma alters the cellular composition of the early fracture callus. J Trauma Acute Care Surg. 2013;74:531-537.

39. Redlich K, Smolen JS. Inflammatory bone loss: pathogenesis and therapeutic intervention. Nat Rev Drug Discov. 2012;11:234-250.

40. Reikeras O, Shegarfi H, Wang JE, Utvag SE. Lipopolysaccharide impairs fracture healing: an experimental study in rats. Acta Orthop. 2005;76:749-753.

41. Reino DC, Palange D, Feketeova E, Bonitz RP, Xu DZ, Lu Q, Sheth SU, Peña G, Ulloa L, De Maio A, Feinman R, Deitch EA. Activation of toll-like receptor 4 is necessary for trauma hemorrhagic shock-induced gut injury and polymorphonuclear neutrophil priming. Shock. 2012;38:107-114.

42. Schlundt C, Schell H, Goodman SB, Vunjak-Novakovic G, Duda GN, Schmidt-Bleek K. Immune modulation as a therapeutic strategy in bone regeneration. J Exp Orthop. 2015;2:1.

43. Schmidt-Bleek K, Schell H, Schulz N, Hoff P, Perka C, Buttgereit F, Volk HD, Lienau J, Duda GN. Inflammatory phase of bone healing initiates the regenerative healing cascade. Cell Tissue Res. 2012;347:567-573.

44. Stegemann JP, Verrier S, Gebhard F, Laschke MW, Martin I, Simpson H, Miclau T. Cell therapy for bone repair: narrowing the gap between vision and practice. Eur Cell Mater. 2014;27:1-4.

45. Takayanagi H. Osteoimmunology: shared mechanisms and crosstalk between the immune and bone systems. Nat Rev Immunol. 2007;7:292-304.

46. Valverde-Franco G, Liu H, Davidson D, Chai S, ValderramaCarvajal H, Goltzman D, Ornitz DM, Henderson JE. Defective bone mineralization and osteopenia in young adult FGFR3-/mice. Hum Mol Genet. 2004;13:271-284.

47. Wu AC, Raggatt LJ, Alexander KA, Pettit AR. Unraveling macrophage contributions to bone repair. Bonekey Rep. 2013;2:373.

48. Wythe SE, Nicolaidou V, Horwood NJ. Cells of the immune system orchestrate changes in bone cell function. Calcif Tissue Int. 2014;94:98-111.

49. Yuan R, Geng S, Chen K, Diao N, Chu HW, Li L. Low-grade inflammatory polarization of monocytes impairs wound healing. J Pathol. 2016;238:571-583.

50. Zuckerman SH, Bendele AM. Regulation of serum tumor necrosis factor in glucocorticoid-sensitive and -resistant rodent endotoxin shock models. Infect Immun. 1989;57:3009-3013. 